\title{
DAVID HUME FRENTE A LA TEORÍA DEL "AMOR PROPIO" DE BERNARD MANDEVILLE \\ Cristina Ríos Espinosa*
}

RESUMEN: En este trabajo se analiza la crítica de David Hume al sistema del "amor propio" de Mandeville; se comparan críticamente dos sistemas de moralidad, el mandevilliano y el humeano: dos versiones contrarias del utilitarismo, la de Hume que considera a la felicidad pública como algo deseable en sí, frente al utilitarismo de Mandeville, que promueve la indiferencia ética en tanto el bienestar público es valorado como un medio para lograr la felicidad privada. Esta investigación defiende la tesis de que tanto Hume como Mandeville justifican la desigualdad social como necesaria para el progreso, el surgimiento del gobierno y de la justicia.

\section{গ৯ల}

ABSTRACT: In this article we analyze David Hume's criticism of Mandeville's self-esteem theory. In addition, we will critically analyze both Mandeville and Hume's morality systems: two different versions of utilitarianism. While Hume's version considers public happiness desirable, Mandeville advocates ethical indifference regarding public well-being and regards it as a means to achieve private happiness. This research defends the theory that both Hume and Mandeville justify social inequality as a necessary tool for progress, the origins of government, and justice.

PALABRAS CLAVE: moralidad, amor propio, felicidad, egoísmo, utilitarismo político, justicia, vicio, virtud, interés.

KEYWORDS: morality, self-esteem, happiness, egoism, political utilitarianism, justice, vice, virtue, interest.

RECEPCIÓN: 15 de agosto de 2009.

APROBACIÓN: 22 de abril de 2010.

* Instituto Cultural Helénico, A.C. 
La reproducción total o parcial de este artículo se podrá hacer si el ITAM otorga la autorización previamente por escrito. 


\section{DAVID HUME FRENTE A LA TEORÍA DEL "AMOR PROPIO" DE BERNARD MANDEVILLE}

\section{Mandeville en la Historia de las Ideas}

Cuando, al comenzar la tarea de investigar acerca de la filosofía del siglo dieciocho, se piensa en los grandes pensadores de la época, la lista apenas incluye a Bernard Mandeville, autor poco conocido y muy incomprendido, pues ninguno de sus ensayos posee el renombre del que gozaron Hume o Adam Smith, por ejemplo. Sin embargo, un examen más cercano revela una de las mentes más importantes de las primeras tres décadas del siglo dieciocho; la lectura de $L a$ Fábula de las Abejas ${ }^{1}$ contiene ideas que formaron parte del debate político y religioso de su tiempo, así como teorías sociales que serán asociadas posteriormente en la historia con Voltaire, David Hume y Adam Smith. Desconocido por la mayoría salvo por algunos cuantos especialistas, aun así ejerció una marcada influencia en el pensamiento de su época. Hizo su debut como satirista político en su tierra natal, Holanda, pero luego se dedicó a traducir las fábulas de La Fontaine, con el objetivo aparente de mejorar su inglés. Mandeville emigró de Holanda a Inglaterra debido a sus filiaciones políticas. Cercano a su muerte, en 1732, había escrito dieciséis trabajos separados; colaboró en la revista The Female Tatler y escribió en diversos estilos que incluyen versos satíricos, fábulas, ensayos y diálogos. Su importancia radica, entre otras cosas, en haber

${ }^{1}$ Editada por primera vez con ese nombre en 1714 y reeditada en 1723 con un segundo volumen por demás polémico. 
descubierto, en mi opinión, una ética de la honorabilidad, que funda las relaciones cívicas y el surgimiento de la esfera pública, ${ }^{2}$ pero además, en plantear la tesis acerca de un orden espontáneo en las sociedades, que sirve de antecedente al postulado sobre la "espontaneidad de las instituciones" de Smith en su Riqueza de las Naciones, de la "mano invisible" del mercado y también de la teoría evolucionista de las sociedades de Friedrick Hayek. Se podría decir que este teórico contemporáneo del liberalismo económico es un mandevilliano del siglo XX.

\section{Crítica de Hume al sistema del "amor propio" de Mandeville}

Vamos a comparar críticamente dos sistemas de moralidad: el mandevilliano, que sostiene que la tendencia hacia la felicidad de los demás se fundamenta en el "amor propio" y en el egoísmo; y el humeano, que se opone a ello diciendo que, si bien la distinción moral y los sentimientos de aprobación moral se deben a la utilidad de las acciones para proporcionar felicidad pública, su fundamento no es egoísta, sino todo lo contrario, descansa en un "sentimiento humanitario" natural. ${ }^{3}$ Compararemos dos versiones distintas del utilitarismo, la de Hume, que considera a la felicidad pública como algo deseable en sí, es decir, como un fin en sí mismo, mientras que el utilitarismo mandevilliano tomaría el

${ }^{2}$ La esfera pública, en este caso específico, es la sociedad comercial organizada y la opinión pública; esta última debe entenderse como aquello que el mercado aprueba intersubjetivamente, gracias a lo cual es posible la formación de la identidad subjetiva, la cual incluye el intercambio mercantil, pues sin esa aprobación intersubjetiva los bienes no se podrían transformar en mercancías y por tanto no se cumpliría el proceso de valorización de las mercancías hacia su plena realización como dinero.

${ }^{3}$ Este "sentimiento humanitario" es análogo al "sentimiento público" compartido por las teorías de Shaftesbury y Hutcheson. En las traducciones del inglés al castellano de las Investigaciones sobre los principios de la moral, este "sentimiento humanitario" se traduce por benevolencia y se entiende como la tendencia a favorecer el bienestar de la sociedad; a veces es el sentido activo de promoverlo, pero también se refiere al sentimiento de agrado resultante de la contemplación de las cualidades en otros, o cuando a alguien le va bien y saca provecho de sus propias cualidades. Es análogo al sentimiento de belleza en la experiencia estética. Hume cree que la utilidad y el provecho están ligados a la belleza. 
bienestar público tan sólo como un medio para lograr la felicidad privada, no como un fin en sí ante el cual el sujeto permanece indiferente. ${ }^{4}$

La moralidad humeana pone a los sentimientos como el fundamento de nuestras distinciones entre vicio y virtud, en contraposición a los sistemas morales racionalistas, que ponen a la razón como el principio de la moralidad. El bien y el mal moral son relativos a nuestros sentimientos, "no hay nada en sí mismo estimable o despreciable", según Hume, con lo cual estaría afirmando una tesis defendida por Mandeville. Otra analogía entre ambos pensadores la encontramos en la afirmación de Hume acerca de cómo algunas virtudes morales surgen de la educación y fueron promovidas por los políticos para favorecer la sociabilidad de la insociabilidad humana, como podemos observar en la siguiente cita:

Tanto los escépticos del mundo antiguo como los modernos han inferido fácilmente de la utilidad manifiesta de las virtudes sociales que todas las distinciones morales surgen de la educación y fueron inventadas en un primer momento y luego fomentadas por la habilidad de los políticos, y ello con vistas a hacer tratables a los hombres y mitigar su egoísmo y ferocidad naturales. ${ }^{5}$

Para Mandeville, la moral es un producto de la educación promovida principalmente por los legisladores, quienes tamizan el egoísmo natural:

Es evidente que los primeros rudimentos de moralidad introducidos por hábiles políticos, para hacer que los hombres se ayudaran unos a otros sin dejar de ser dóciles, fueron maquinados principalmente con el fin de

${ }^{4}$ Debo aclarar que el hecho de que Hume afirme que muchas acciones nos agradan porque son útiles no implica que sólo nos movamos con base en este fin como último y que toda virtud deba ser juzgada de acuerdo a su utilidad; es lo que diferencia la propuesta humeana del utilitarismo mandevilliano, como lo intento probar en esta investigación. No estamos frente a un utilitarismo radical: de hecho, Hume sostiene la posibilidad de que el fin hacia el que tendemos no sólo nos agrade como medio, sino también como fin en sí mismo.

${ }^{5}$ David Hume, Investigación sobre los principios de la moral, 1991, Madrid, Espasa Calpe, trad. Gerardo López Sastre, Sección V, “¿Por qué agrada la utilidad?”, Parte I, párrafo 3, p. 81 . 
que los ambiciosos pudieran obtener el mayor beneficio posible y gobernar sobre gran número de individuos con toda facilidad y seguridad. ${ }^{6}$

Si bien Hume comparte con Mandeville la idea de que el hombre posee un egoísmo natural que nos hace insociables, así como la idea de que las virtudes sociales se promueven por la educación, y el agente civilizador en este caso es el político, Hume va más allá de Mandeville porque no se queda en este nivel de la moralidad. Si rastreamos más a fondo la moralidad humeana nos encontramos con una diferencia fundamental, pues para Hume efectivamente algunas aversiones o sentimientos de aprobación y censura son invenciones de la educación; sin embargo, no todos provienen de ella: existen algunos que implican un principio natural de moralidad en los hombres, pues de lo contrario sería imposible que un afecto moral tuviese efecto en nosotros. Hume argumenta que no todo sentimiento de aprobación o censura tiene su origen en el interés propio, pues un ser humano siente simpatía por la imagen de la felicidad social, aun cuando no esté relacionado con nuestro amor propio y nuestra utilidad: "Hasta tal punto se parece toda la humanidad al principio bueno que [...] siempre nos inclinamos, en virtud de nuestra filantropía natural, a conceder preferencia a la felicidad de la sociedad y [...] a la virtud sobre su opuesto". ${ }^{7}$ De manera que no siempre entra en juego nuestro interés; esta idea no es compartida por Mandeville, para quien toda acción en favor del interés público se deriva del amor propio, y no cree en la posibilidad de un sentimiento de benevolencia genuino hacia los demás, a diferencia de Hume, quien para probar la universalidad de los sentimientos morales, recurre a la experiencia de agrado que brinda la contemplación estética; con ello muestra cómo los sentimientos de agrado y aprobación surgen de manera común en los hombres. Para Hume, el sentimiento público es posible y le parece ingenuo derivarlo exclusivamente del interés privado, con lo que estaría

${ }^{6}$ Bernard Mandeville, "Investigación sobre el origen de la virtud moral”, en La Fábula de las abejas o los vicios privados hacen la prosperidad pública, 1982, México, Fondo de Cultura Económica, trad. José Ferrater Mora, p. 26.

${ }^{7}$ David Hume, Investigación sobre los principios de la moral, op. cit., Parte II, párrafo 23 , p. 95 . 
criticando la teoría del amor propio de Mandeville, entre otros escépticos morales con los cuales dialoga en este ensayo.

Las analogías y diferencias entre ambos autores podemos rastrearlas principalmente en la comparación entre dos ensayos, el de la "Investigación sobre el origen de la virtud moral" que aparece dentro de La fábula de las abejas de Mandeville y la Investigación sobre los principios de la moral de Hume, aunque no únicamente como veremos más adelante. El método empleado por ambos autores es empírico, parten de la observación del comportamiento de la sociedad, si bien el origen de la moralidad puede ser social, como vemos que comparten entre ellos. Hume, a diferencia de Mandeville, sí llega a plantear la universalidad del sentimiento moral por medio de la contemplación estética. Parece que en Hume la benevolencia es un principio natural en el hombre, condición necesaria para que éste sea afectado de alguna manera, de lo contrario sería imposible aprender las virtudes sociales, que son los usos y costumbres que embellecen a una sociedad y que dirigen la conducta, aunque el sujeto no esté muy convencido de ellas; no obstante, las observa para poder lograr la comunicación y diálogo con los demás, es decir, para hacerlo un ser sociable.

Toda la argumentación de Hume prueba que los sentimientos de aprobación o desaprobación de las acciones no sólo se fundan en la utilidad, a diferencia de la tesis mandevilliana, sino que tienen un principio universal e innato en la estructura humana, como es la benevolencia. Hume responde críticamente a los escépticos, entre ellos a Mandeville, y sólo les complacerá en el método empleado para probar la universalidad del sentimiento moral, el cual será empírico, pero se distancia de ellos en las conclusiones:

Consideremos la cuestión "a posteriori" [...] investiguemos si el mérito de las virtudes sociales no se deriva en gran medida de los sentimientos de humanidad con que afectan a los espectadores. Parece que es una cuestión de hecho que [...] la circunstancia de la utilidad es una fuente de alabanza y aprobación; [...] que es la única fuente de esa alta consideración que se presta a la justicia, a la fidelidad, al honor, a la 
lealtad y a la castidad [...] inseparable de todas las demás virtudes sociales [...] que es el fundamento de la parte principal de la moral. ${ }^{8}$

Pero aún cuando en nuestra aprobación exista una tendencia útil de las virtudes sociales, aún así "no nos mueve por consideraciones de interés personal, sino que tiene una influencia más universal y dilatada". ${ }^{9}$ Hume sigue insistiendo en que existe en nuestra naturaleza una tendencia hacia el bien público porque afecta a "los principios benevolentes de nuestra constitución". Separa el principio de la benevolencia, que es natural, de los de la simpatía, que dependen de nuestra cercanía del objeto y que fomenta el sentimiento. No está de acuerdo en que la moralidad tenga como único fundamento a la utilidad, el amor propio y el interés. Para Hume nuestros sentimientos morales son un compuesto de benevolencia y simpatía y nos capacita para aplaudir o censurar una acción, es decir, nos capacita como jueces.

Al tratar la moralidad, Hume no nos habla de rigores, austeridades inútiles, sufrimiento y autonegación; su propósito es mostrar que el ser humano no se separa del placer a menos que se le compense, en lo que coincide con la postura mandevilliana. El imperativo moral humeano consiste en un esfuerzo que exige un cálculo exacto y una preferencia por la máxima felicidad; estamos frente a una racionalidad entendida como la obtención de la máxima felicidad. Mandeville también considera el sistema de compensaciones como el móvil de la acción humana y a la utilidad como el fundamento de las virtudes sociales; encuentra en el egoísmo el origen de la sociabilidad, a diferencia de Hume, para quien el mérito o la aprobación de una acción dependen de su tendencia a promover la felicidad humana, lo cual va más allá del interés personal. Los sistemas de moralidad de Hume y Mandeville poseen una función liberadora, en tanto están adecuados a nuestra naturaleza humana al no exigirnos la autonegación de las pasiones; en ambas teorías, los valores de la religión aparecen como irracionales e inútiles. Frente al debilitamiento de las religiones y de la muerte de Dios, no nos queda más que consultar a nuestra propia naturaleza, los sentimientos se convierten

${ }^{8}$ David Hume, Investigación sobre los principios de la moral, Parte II, párrafo 25, p. 99.

${ }^{9}$ Ibid., Sección V, “Por qué agrada la utilidad?”, Parte II, párrafo 26, p. 99. 
en la dirección y guía hacia la felicidad. Ambos enfatizan los sentimientos morales para suavizar las pasiones humanas y el papel secundario jugado por la razón; mientras que para Mandeville se limita al cálculo eficientista de los medios, para Hume se coloca en la perspectiva de la voluntad -a diferencia del estado privilegiado de la razón en los sistemas de moralidad anteriores-; ambos combaten la inutilidad de las "virtudes monacales" que le imponen rigores innecesarios al cuerpo y a los hábitos sociales.

\section{Crítica de Hume a la ambigüedad del concepto de vicio de Mandeville}

La crítica de Hume, compartida también por Adam Smith, contra Mandeville, se dio en el mismo sentido que en Hutcheson, quienes lo acusan de ambigüedad conceptual. Hume le objeta la ausencia de un referente epistemológico suficientemente sólido en el cual fundar el sentido de las conductas humanas; ese referente valorativo consistiría en determinar aquello que es digno de elogio (praiseworthy), es decir, ¿qué acciones son consideradas valiosas?, ¿cómo un sujeto se convierte en objeto de alabanza? La valoración debe recaer en aquello que la sociedad considera digno de alabanza; los sentimientos de aprobación de las conductas dependen de la utilidad de una acción que tenga como fin la felicidad humana; éstos no surgen de la educación en primera instancia, ni de una manipulación política como sostenía Mandeville, sino de un "sentido moral innato", a saber, el "sentimiento humanitario" como condición previa a la educación moral y de las costumbres; estas últimas coadyuvan al logro de la virtud, pero son secundarias y necesitan de la precondición de un sentido moral (moral sense). No deseamos el aplauso público, como sostiene Mandeville, sino el ser dignos de aplauso como dirán Hume y Smith.

Hume, al igual que Hutcheson, estaba convencido de la dirección moral ofrecida por los sentimientos más que por la razón pura; son aquellos lo que guían los juicios morales de los hombres; creía que el origen de las pasiones animales descansaban en el cuerpo exclusivamente, mientras que en los humanos se podían centrar en la mente o en los objetos externos; en lo que respecta al cuerpo, las mismas cualidades motivaban el orgullo 
(pride) tanto en los animales como en los humanos, ${ }^{10}$ quienes "comparten todos los principios internos" que generan tanto el orgullo como la humildad, el modo de operación de las causas es el mismo y Mandeville comparte esta misma opinión.

Hume sostenía que no alabamos las acciones por su ejecución, sino de acuerdo a los motivos que las producen, es decir, a sus móviles. Sin embargo, habitualmente consideramos a las acciones mismas como signos que indican los motivos que conducen a un individuo a actuar, ante la imposibilidad de conocer los móviles como también sostenía Mandeville. ${ }^{11}$ Consideraba inexistente la división de la acción en móvil y ejecución, como si se tratara de fenómenos independientes; la acción es un fenómeno unitario y no parcelario, es una totalidad de sentido; el acto es un signo que indica los motivos, ${ }^{12}$ no hay otra forma de acceso a estos últimos más que en un plano práctico expresivo. No obstante, siguiendo la línea de argumentación de Bayle, ampliada por Mandeville, Hume juzga que es un error creer que damos nuestra aprobación a los demás porque estemos naturalmente complacidos cada vez que nos enfrentamos a acciones que consideramos virtuosas, como sugería Hutcheson, esto sería un absurdo: $:^{13}$

Parece entonces, que todas las acciones virtuosas derivan su mérito sólo de motivos virtuosos, y son considerados solamente como signos de esos motivos. De este principio concluyo que el primer motivo virtuoso que permanece como virtud en cualquier acción, nunca puede derivarse

${ }^{10}$ Hume hace una clara distinción del orgullo, a diferencia de Mandeville; esta pasión es necesaria para formarnos una estima propia: es mejor un hombre orgulloso que uno desprovisto de estima.

${ }^{11}$ Mandeville suponía al egoísmo y al orgullo como los motores de la acción, lo cual lo lleva a poner en duda la posibilidad de la existencia de la virtud privada, entendida ésta como el sometimiento de las pasiones, la abnegación o negación del yo. Además había demostrado lo inútil de las creencias religiosas o de algún ideal regulador de las acciones prácticas, pues en esto el hombre mostraba una incongruencia.

${ }^{12}$ Mandeville no puede efectuar esta unificación entre la teoría y la praxis como hace Hume en su consideración del acto como signo de la motivación, como un fenómeno unitario pleno de sentido. Para Mandeville, estos dos fenómenos estaban separados o fragmentados, de ahí la paradójica naturaleza humana y la inutilidad de las religiones para promover el bien y la felicidad humana: el hombre no puede seguir los dictados de sus ideales.

${ }^{13}$ Aunque también existen virtudes "naturales", como ya vimos antes cuando defiende un principio de benevolencia innato en la constitución humana. 
de la mera observación de la virtud de dicha acción, sino de un principio o motivo natural. Suponer que la mera consideración de la virtud de una acción sea el primer motivo que produjo la acción y catalogarla virtuosa por eso, es razonar en círculo. Antes de tener esa consideración, la acción debe ser realmente virtuosa; y esta virtud debe derivarse de un motivo virtuoso. Y como consecuencia, el motivo virtuoso debe diferenciarse de la consideración de la virtud de una acción. Una acción debe ser virtuosa antes de que sea vista o considerada virtuosa. Un motivo virtuoso es requisito para volver a una acción virtuosa. Entonces, un motivo virtuoso debe ser el antecedente necesario de la consideración. ${ }^{14}$

Cada vez que tomamos en consideración cuestiones morales, el origen de las categorías de la virtud y el vicio deben buscarse en algún motivo de la naturaleza humana que sea lógicamente distinto del sentido de su moralidad. Hume argumentó que el hecho de que las personas ocasionalmente actúan de acuerdo con lo que sinceramente experimentan como un "sentido del deber" o de la moralidad, sólo puede ocurrir -tal como Mandeville sostenía- en un estado de civilización en el cual todas las acciones humanas están condicionadas con mucha fuerza por el poder de la educación, el hábito y la costumbre, de manera que el "sentido moral" (moral sense) se convierte en una segunda naturaleza. Y aun cuando se le conceda a Hutcheson razón en suponer que algunos sentimientos benevolentes proceden de un motivo natural, las reglas de la justicia que, por ejemplo, obligan a alguien a pagar una deuda, no tenían un origen natural para dar cuenta de su aplicación universal e incondicional. Por esta razón, dichas reglas tenían que derivarse artificialmente (convencionalmente), en el sentido de no originarse directamente de las emociones humanas ni de acuerdo con ellas, sino que eran incorporadas a través de la mediación de las instituciones sociales existentes. Tal como Hume le escribe a Hutcheson:

No puedo estar de acuerdo con su sentido de Natural, por estar fundado en causas finales, lo cual es una consideración que me parece

${ }^{14}$ David Hume, A Treatise of Human Nature, 2001, Oxford Philosophical Texts, Oxford University Press, ed. David Fate Norton \& Mary J. Norton, Book III, Part II: "Of justice and injustice"; Sect. I, par. 4, p. 307. Traducción mía. 
CRISTINA RÍOS ESPINOSA

muy incierta y no filosófica. Pues, ¿cuál es el fin del hombre? ¿Es creado para la felicidad o para la virtud? ¿Para esta vida o para la siguiente? ¿Para él o para el Creador? Su definición de Natural depende de que resuelvan estas cuestiones, que son interminables, y muy lejanas a mi propósito. Nunca he llamado a la Justicia antinatural (unnatural), sino tan sólo artificial. ${ }^{15}$

Gracias a esta defensa de la convencionalidad de ciertas características de la sociabilidad, el proyecto de Hume se aparta del de Hutcheson y se emparenta con el de Mandeville. Coincide con este último en un hecho fundamental, en el reconocimiento de la dirección política de los sentimientos, no obstante su inclinación en favor de un proceso natural de estos últimos. Los sentimientos humanos son dirigidos adecuadamente por hábiles legisladores, en función de gobernar mejor a los hombres y de preservar la paz en la sociedad; por ello han luchado por generar un valor y un apego por la justicia. ${ }^{16}$ Sin embargo, critica a Mandeville por atribuirle exclusivamente a la labor política la instauración de las nociones de honor y vergüenza:

Algunos filósofos han atribuido toda distinción moral al resultado del artificio y la educación, cuando los hábiles políticos buscan restringir las pasiones violentas de los hombres y los hacen operar a favor del bien público, mediante las nociones del honor y la vergüenza. Sin embargo, este sistema es inconsistente, pues si los hombres no contaran con un sentimiento natural de aprobación y culpa nunca podrían ser persuadidos por los políticos, ni serían inteligibles palabras como laudable, culpable, odioso o digno de alabanza, sería un lenguaje perfectamente desconocido para ellos. ${ }^{17}$

${ }^{15}$ David Hume, The Letters of David Hume, 1932, Oxford, Oxford University Press, editadas por J. Y. T Grieg, 2 vols., I, p. 33. La justicia es convencional, es decir, su génesis descansa en las condiciones de escasez cuando en el avance de la civilización, poblaciones en ascenso tuvieron que competir por recursos naturales, lo que dio lugar a luchas en la competencia por la sobrevivencia, lo cual hizo necesaria la formación de instituciones que ayudaran a preservar el orden y a neutralizar la violencia de los hombres viviendo en sociedad. La justicia es una virtud artificial en el sentido aludido.

${ }^{16}$ David Hume, A Treatise of Human Nature, op. cit., Book III, Part II, Section ii; Par. 25, p. 321.

${ }^{17}$ Ibid., p. 321. 
En efecto, Hume no estaba totalmente en contra de la antropología especulativa de Mandeville, no lo moralizaba, su crítica era más científica al centrarse en sus aspectos lógicos o epistemológicos; juzgaba imposible la pretensión de Mandeville de fundar en la tarea política la distinción entre vicio y virtud, pues si la naturaleza no nos ayudara en este asunto, sería inútil que los políticos hablaran de honorable, vergonzoso, digno de alabanza o de culpa, lo que quiere decir que si los hombres no respondieran directamente a un lenguaje moral, ${ }^{18}$ el discurso político habría caído en oídos sordos, esto es, que debió haber existido un referente, un elemento constitutivo de la naturaleza previo a la educación, una sensibilidad natural a la cual apelaba cualquier intento de instrucción de los hombres; de lo contrario, el aprendizaje carecería de efectividad práctica. En realidad está apelando a un moral sense sin el cual se torna imposible la educación moral, el cual incluye un gusto moral, como aquello que la sociedad considera valioso, un lenguaje moral compartido por todos sus miembros.

\section{La génesis de la sociabilidad y el utilitarismo como fuente de los sentimientos morales}

En la filosofía moral humeana, las virtudes sociales poseen una utilidad natural que antecede a todo precepto o educación; en cambio, en la moralidad mandevilliana las virtudes públicas son meramente un producto de la educación. Hume reconoce el papel de la educación para promover las virtudes sociales, pero siempre como algo derivado de aquella precondición llamada sentido moral, es decir, la existencia de una disposición natural en el hombre que le posibilita el ser afectado por la educación o el ser manipulable por la política, esto es su carácter de "ser afectado" no

${ }^{18}$ Me parece que Hume se está refiriendo al carácter de "ser afectado" que el hombre posee de manera natural, es decir, el hombre conserva una disposición natural para recibir todo aprendizaje moral. No niega el poder de la educación en la moralidad y sociabilidad humana, pero lo considera como un carácter derivado del hecho primario de que somos capaces de "ser afectados". De no ser así, los políticos habrían fracasado en sus intentos por sociabilizar a la humanidad. 
CRISTINA RÍOS ESPINOSA

es aprendido, sino innato, de no ser así sería inútil la sociabilidad, sería imposible convertirlo en un ser tratable y civilizado.

En oposición a Mandeville, Hume niega la egoísta adhesión a las virtudes sociales. Nuestra aprobación moral posee un carácter trascendente en el sentido de ir más allá de la esfera privada de nuestros intereses:

La utilidad es agradable y provoca nuestra aprobación [...] Pero ¿útil? ¿Para qué? Para el interés de alguien ciertamente. ¿Para el interés de quién? No solamente para el nuestro. Porque nuestra aprobación frecuentemente se extiende más lejos [...] debe ser el interés de aquellos a quienes sirve el carácter o la acción aprobada; y estos individuos [...] por muy distantes que estén de nosotros, no nos resultan completamente indiferentes. ${ }^{19}$

La aprobación moral depende de la tendencia hacia el interés de los demás, pues si sólo incluyera el interés subjetivo, la acción carecería de moralidad. Hume rechaza al "amor propio" como el principio unificador entre el interés privado y el público; no es la verdadera fuente de la moralidad. El mérito de una acción descansa en su tendencia a favorecer la felicidad de la humanidad, ${ }^{20}$ sólo así surge el "sentimiento humanitario" que aprobamos y estamos dispuestos a alabar:

El amor a uno mismo es un principio en la naturaleza humana de una energía tan vasta, y el interés de cada individuo está [... tan estrechamente ligado con el de la comunidad, que se puede disculpar a estos filósofos que imaginaron que toda nuestra preocupación por el bien público podía resolverse en una preocupación por nuestra propia conservación y felicidad. ${ }^{21}$

Esta cita es una clara referencia a la postura moral de Mandeville; Hume no acepta el poder sintético del "amor propio" para armonizar la

${ }^{19}$ David Hume, Investigación sobre los principios de la moral, op. cit., Sección V: “¿Por qué agrada la utilidad?", Parte I, párrafo 14, p. 85.

${ }^{20}$ Esta "felicidad de la humanidad" no se refiere a la de la humanidad como conjunto de personas, sino como "naturaleza" humana en el sentido más científico y no filosófico" del término.

${ }^{21}$ Hume, op. cit., Sección V: “¿Por qué nos agrada la utilidad?”, Parte II, párrafo 1, p. 86. 
multiplicidad de intereses particulares con el interés general de la humanidad, al contrario, éstos siempre están en tensión. Hace un esfuerzo por demostrar cómo, aún cuando no sean armonizables, ello no agota nuestros sentimientos morales: "tenemos que renunciar a la teoría que da cuenta de todo sentimiento moral acudiendo al principio del amor a uno mismo. Tenemos que admitir un afecto más general y conceder que los sentimientos de la sociedad no nos resultan totalmente indiferentes". ${ }^{22}$

Hume intenta demostrar cómo nuestros sentimientos morales no se originan en el "amor propio", sino en un principio más general y trascendente que no se agota en el sujeto, sino que va más allá de él. Para probarlo recurre a una demostración lógica, que dicta que aun cuando a la utilidad le interesa la adecuación de los medios hacia un fin -lo cual es agradable de admirar y suscita nuestra aprobación-, sería una contradicción no interesarnos también por el fin como algo agradable en sí. Desinteresarnos por el fin sería irracional; el interés por los medios debe incluir un interés por el $\mathrm{fin}^{23}$ para que el principio de utilidad sea congruente:

La utilidad es sólo una tendencia hacia un cierto fin; y es una contradicción en los términos que una cosa nos agrade como medio para un fin, cuando el fin mismo no nos afecta de algún modo. Si la utilidad, por tanto, es una fuente de sentimiento moral, y si esta utilidad no se considera siempre con referencia a un yo, se sigue que toda cosa que contribuya a la felicidad de la sociedad se recomienda a sí misma directamente para nuestra aprobación y buena voluntad. ${ }^{24}$

Hume acepta que la utilidad sea una fuente de sentimiento moral, pero niega que a este último le sea indiferente un fin más allá del sujeto; es decir, la felicidad o el bienestar público es recomendable en sí mismo y no por su referencia a un interés privado. La aprobación de la felici-

${ }^{22}$ Hume, op. cit., Sección V, “¿Por qué nos agrada la utilidad?”, Parte II, párrafo 2, p. 87.

${ }^{23}$ Nótese aquí de manera importante la diferencia entre el utilitarismo humeano y el mandevilliano: mientras que para Hume la "racionalidad de la utilidad" no se agota en interesarse en los medios adecuados para la realización de un fin, sino además en el fin mismo, para Mandeville se agota en la elección de los medios adecuados, siendo indiferente el fin en sí mismo.

${ }^{24}$ Hume, op. cit., Sección V, “¿Por qué nos agrada la utilidad?”, Parte II, párrafo 2, p. 87. 
CRISTINA RÍOS ESPINOSA

dad social no depende de su utilidad personal, sino que trasciende la subjetividad. El interés por la sociedad está incluido en nuestro propio interés, el destino de la humanidad afecta vivamente nuestra imaginación, la naturaleza humana posee una simpatía social. Es optimista con respecto a la naturaleza humana, pues reconoce la existencia de una inclinación natural hacia la felicidad del otro. En cambio, Mandeville niega esta inclinación natural en la constitución humana, pues considera que la preocupación por los demás es el resultado de un aprendizaje social y tan sólo un medio para la propia realización, en lugar de un fin en sí mismo.

\section{El principio de la simpatía humeano como fuente de aprobación moral}

La "opinión pública" en la moralidad humeana juega un papel importante al igual que en la "ética política" mandevilliana, sólo que con la diferencia de que en la primera es necesario un imaginario cambio de posiciones (simpatía) para que la conversación y el intercambio de opiniones sea posible: es la única manera de tomar en cuenta la postura intelectual del interlocutor. La comunicación sería imposible si no pasáramos por alto nuestras diferencias:

Todos los días nos encontramos con personas que están en una situación diferente de la nuestra y que nunca podrían conversar con nosotros si permaneciéramos continuamente en esa posición y punto de vista que nos es peculiar. Por tanto, el intercambio de opiniones en la sociedad y en la conversación nos hace formar un criterio general e inalterable, mediante el que podemos aprobar o desaprobar caracteres y conductas. ${ }^{25}$

La aprobación moral de la virtud o el rechazo del vicio responden a este carácter relacional de los hombres por medio de la simpatía y la conversación. Hume busca probar cómo la aprobación o censura moral no puede fundarse en principios abstractos, sino que es necesaria la comunicación empática intersubjetiva para posibilitar los sentimientos

${ }^{25}$ Hume, op. cit., Sección V, “¿Por qué nos agrada la utilidad?”, Parte II, párrafo 25, p. 97. 
de aprobación y el intercambio de los aplausos en la alabanza de algo que previamente es considerado "objeto de alabanza", es decir, de aquello que la sociedad considera valioso o meritorio de las conductas humanas:

La naturaleza ha dispuesto sabiamente que las relaciones privadas prevalezcan $[\ldots]$ sobre las consideraciones y los puntos de vista universales; de otra manera nuestras acciones y afectos se disiparían y perderían por falta de un objeto limitado y conveniente. ${ }^{26}$

Hume deduce un principio de benevolencia originario en nuestra constitución natural del hecho de cómo nuestro carácter es "objeto de influencia" ante el dolor y el placer humanos; sostiene que el "sentimiento de benevolencia" es un principio innato, general y universal sobre el cual se fundan nuestros sentimientos morales. Con esta postulación, se opone a las teorías del "amor propio" que afirman que la única fuente de moralidad es el "interés propio" y que el hombre es indiferente a los demás:

Tenemos que concluir "a priori", que es imposible para una criatura como el hombre el ser totalmente indiferente al bienestar o malestar de sus semejantes $[\ldots]$ aquí $[\ldots]$ están las primeras nociones, temas o ideas generales de una distinción general ante las acciones. ${ }^{27}$

Esta imposibilidad de una indiferencia ética Hume la prueba con la diferencia de grados en que somos afectados ante la lejanía o cercanía de los objetos contemplados. El hecho importante que trata de demostrar es cómo el ser humano posee una precondición natural que consiste en su carácter de "ser afectado"; además, demuestra por medio de un análisis "a posteriori" un común en las conductas meritorias, a saber, la utilidad social y el "sentimiento humanitario", que tiene en cuenta la felicidad de la mayoría: "en nuestra aprobación general de caracteres y costumbres, la tendencia útil de las virtudes sociales no nos mueve

${ }^{26}$ Hume, op. cit., Sección V, “¿Por qué nos agrada la utilidad?”, Parte II, párrafo 24, p. 98. La cita se refiere a una nota puesta a pie de página referida al párrafo citado.

${ }^{27}$ Ibid., Sección V, “¿Por qué nos agrada la utilidad?”, Parte II, párrafo 26, p. 98. 
CRISTINA RÍOS ESPINOSA

por consideraciones de interés personal, sino por una influencia mucho más universal y dilatada". ${ }^{28}$

La utilidad es un principio universal a diferencia del "amor propio"; dicha utilidad social es el fundamento "a posteriori" para nuestra aprobación moral, la cual va más allá del interés privado. Dicho "principio de utilidad social" posee una tendencia de rebasamiento de la esfera privada, y por tanto posee carácter de universalidad. Ahora bien, además de este principio de utilidad "a posteriori”, Hume descubre una condición "a priori” que posibilita nuestro ser moral, a saber, nuestro carácter de "ser afectados" por los sentimientos de otros, que es previo incluso al principio de la simpatía smithiano, ${ }^{29}$ que es la base de la comunicación intersubjetiva. De esa capacidad de ponerse en el lugar del otro, en ese imaginario cambio de posiciones está el origen de la comunicación social. La utilidad humeana es un principio universal "puesto que [...] es imposible agradar como medio para un fin cuando el fin resulta totalmente indiferente", a diferencia del utilitarismo mandevilliano. Hume continúa oponiéndose a la tesis de los escépticos modernos que sostienen que el "amor propio" es el origen de la moralidad: "nunca puede ser el amor a uno mismo lo que haga que su visión resulte agradable para nosotros, los espectadores, e impulse nuestra estima y aprobación". ${ }^{30}$ Cree posible la existencia de un sentimiento natural a favor del otro sin estar fundado primariamente en el "interés propio". Aprobamos a una persona que posee alguna cualidad aún cuando nosotros no derivemos de ello ningún placer. No toda acción en favor de los demás parte del egoísmo sino de la simpatía; este principio abre la posibilidad de la existencia de acciones benevolentes. Los sentimientos de los otros jamás me afectarían más que cuando se transforman en algo nuestro: si dichos sentimientos se quedarán como ajenos jamás tendrán influencia en nosotros.

A diferencia de Mandeville, Hume no se queda encerrado en la "heteronomía”, en tanto el juicio de valoración moral de una acción no depende

${ }^{28}$ Hume, op. cit., Sección V, “¿Por qué nos agrada la utilidad?”, Parte II, párrafo 28, p. 99.

${ }^{29}$ En realidad ese carácter de "ser afectados" de manera natural sería aquello que posibilita un principio como la simpatía, porque ¿cómo puedo ponerme en el lugar del otro si no poseo un sentido moral previo como condición de posibilidad de todas las virtudes sociales?

${ }^{30}$ Hume, op. cit., Sección VI, "De las cualidades útiles a nosotros mismos", Parte I, párrafo 3, p. 102. 
de manera absoluta de la aprobación pública, sino de la transformación de dicha valoración social en una convicción personal por parte del agente. Dicha transformación de la valoración pública en una convicción personal parecería la formación de un "ideal del yo", en tanto es la conciencia subjetiva quien pone en una balanza el valor de la "opinión pública"; de no ser así, el sujeto quedaría sometido al tribunal del juicio cosificador del público. ${ }^{31}$

\section{La "autoestima" humeana frente a la "vanidad" mandevilliana}

Hume comparte con Mandeville el calificar como vicio las muestras de orgullo excesivo por parte del sujeto, por resultar odioso a los demás de manera universal; ambos reconocen el valor positivo de esta tendencia humana a la sobrevaloración, debido a la utilidad social de estas pasiones de vanidad y orgullo que ayudan a promover la sociabilidad y el intercambio: "las continuas discrepancias de la vanidad y el orgullo de los hombres, cuando están en compañía, han introducido las reglas de las buenas costumbres y la cortesía, [... ] con vistas a facilitar la relación entre las mentes y una conversación y comercio sin perturbaciones". ${ }^{32}$

Hume acepta que la arrogancia daña a los demás, de ahí la necesidad de reglas, como el no monopolizar la opinión sin ceder la palabra y darle oportunidad a otros de expresar sus ideas, una regla democrática que consiste en permitir un equilibrio de libertades en la participación de todos en la "publicidad": 33

En la conversación resulta agradable el espíritu vivo del diálogo [...] De ahí que el narrador de largas historias o el declamador pomposo reciban

${ }^{31}$ Una postulación análoga la encontramos en el "espectador imparcial" smithiano.

${ }^{32}$ David Hume, Investigación sobre los principios de la moral, op. cit., Sección VIII, "De las cualidades inmediatamente amables a los demás”, Parte I, párrafo 1, p. 132.

${ }^{33}$ Estas actitudes liberales e ilustradas en torno a la publicidad, el respeto a la opinión ajena y el derecho de todos a expresar sus ideas -reglas que de ser violadas atentarían contra el principio de la tolerancia-son inconsistentes en la filosofía de Hume si las contrastamos con la legitimación que hace de la desigualdad social en el plano material. La libertad que tanto defiende es la de los propietarios privados, cuyos intereses se identifican con los "intereses de la humanidad". 
CRISTINA RÍOS ESPINOSA

muy poca aprobación. Pues la mayoría de los hombres desean igualmente participar a su vez en la conversación, y ven con muy malos ojos esa locuacidad que les priva de un derecho del que de forma natural son tan celosos. $^{34}$

Hume recomienda la modestia como esa escrupulosidad requerida en el honor, algo contrario a la arrogancia basada en la vanidad; reconoce esa tendencia natural del hombre a sobrevalorarse:

La modestia puede entenderse en diferentes sentidos [...] Algunas veces significa esa delicadeza y escrupulosidad en la que se refiere al honor, ese temor a la censura, ese miedo a entrometerse o causar daño a los demás [...] halaga la vanidad de todos los hombres al presentarles la apariencia de un alumno dócil, que recibe con la adecuada atención y respeto cada palabra que pronuncian. ${ }^{35}$

La modestia será para ambos filósofos la virtud que acompaña el arte de la conversación; permite el respeto de las libertades de los participantes en la publicidad y es la base de la tolerancia defendida por los miembros de la Ilustración, como Voltaire. Este principio de la tolerancia se ve amenazado por la arrogancia, resultado de esa tendencia natural a sobrevalorarse, la cual puede llegar a disolver a la sociedad:

Si se diera vía libre a la autoalabanza y se observara aquella máxima de Montaigne de que uno dijera tan francamente como es seguro que se piensa: soy sensato, tengo conocimientos, valor, belleza, o ingenio; si éste fuera el caso [...] todo el mundo es consciente de que caería sobre nosotros tal torrente de presunciones, que convertirían a la sociedad en totalmente inaguantable. Por esta razón la costumbre ha establecido como una regla del trato público que los hombres no deben dar rienda suelta a la alabanza de sí mismos ni incluso hablar mucho de sí mismos. ${ }^{36}$

${ }^{34}$ David Hume, Investigación sobre los principios de la moral, op. cit., Sección VIII, "De las cualidades inmediatamente amables a los demás”, Parte I, párrafo 5, p. 134.

${ }^{35}$ Ibid., párrafo 8, p. 134-5.

${ }^{36}$ Hume, op. cit., párrafo 9, p. 136. 
La arrogancia se convierte en un vicio que amenaza el espíritu público y la publicidad al romper con los principios de la libertad de expresión. Mandeville considera que ofende a los demás; sin embargo, una correcta conducción nos lleva a moderarla, mas no a eliminarla, permitiéndole una expresión educada en la sociedad, cuyo resultado será el juicio valorativo de aprobación social y la reputación como compensación. Dicho juicio valorativo por el elogio de la sociedad tiene en Mandeville la última palabra, no es así en Hume y Smith, quienes reconocen la necesidad del sujeto de una aprobación de sí mismo, con lo cual evita ser humillado al quedar sometido a los caprichos de la fortuna de la opinión:

Una pequeña propensión hacia la modestia, incluso en el sentimiento interno, es considerada favorablemente [...] Pero esto no excluye un noble orgullo y espíritu, que puede mostrarse abiertamente en todo su alcance, cuando uno es víctima de la calumnia o de la opresión de cualquier clase. ${ }^{37}$

Hume nos está hablando -al igual que harán Mandeville y Smith-de la necesidad de una autoestima saludable para cualquier espíritu. En Mandeville esa tendencia a la sobrevaloración debe ser disfrazada, mas no eliminada, para convertir al sujeto en un ser social; a su exceso de sobrevaloración le llamará vicio; el disfraz de este exceso tampoco es una virtud. Dicha sobrevaloración y el deseo de superioridad humano es la base del progreso y del comercio. Hume estaría de acuerdo, pero con la diferencia de no llamar vicio al "deseo de fama" Mandeville no puede evitar condenar este deseo como vicio debido a su rigorismo teórico. En cambio, el principio de la modestia sí es una virtud para Hume, lo mismo que para Smith, porque no es considerado un disfraz o un acto de hipocresía, sino una moderación interna sincera frente al "tribunal de la conciencia", ${ }^{38}$ mientras que para Mandeville solamente posee un valor como signo exterior en la esfera pública y no posee valor intrínseco.

${ }^{37}$ Ibid., párrafo 10, p. 136.

${ }^{38}$ Esta categoría es de Kant, pero vemos sus rudimentos en la filosofía moral de David Hume y de Adam Smith. 
CRISTINA RÍOS ESPINOSA

La siguiente cita es un ejemplo de cómo Hume considera al "deseo de fama" una virtud útil, a diferencia de Mandeville, quien lo considera un vicio útil: "Está tan lejos de ser censurable un deseo de fama, de reputación o de un buen nombre, que parece inseparable de la virtud, de un gran talento y de una disposición noble y generosa". ${ }^{39}$

Al igual que hará Smith en su Teoría de los sentimientos morales, Hume reconoce que la dignidad de un hombre no es "heterónoma", es decir, no depende del aplauso ni de la opinión pública; podrá influir en la imagen propia, pero sólo como un signo ${ }^{40}$ de estar en lo correcto; es sólo una verificación o certeza de bien pero no quien determina la moralidad de una acción. Hume no estaría de acuerdo con Mandeville en que los móviles del hombre, y su condición de "ser afectado" por la manipulación política, dependan del aplauso y del elogio público de manera absoluta y definitiva, sino de la aceptación y valoración de la conciencia moral:

¿En qué consiste [...] la vanidad que es considerada tan justamente como una falta de imperfección? Parece consistir [...] en una exhibición tan inmoderada de nuestras ventajas, honores y realizaciones; con una demanda tan abierta y pesada de elogio y admiración, que resulta ofensiva para los demás e invade demasiado su ambición y vanidad secretas $[\ldots]$ indicio seguro de la falta de la verdadera dignidad y elevación de espíritu [... Porque, ¿a qué viene ese impaciente deseo de aplauso, como si no tuvierais un justo título al mismo y no pudierais razonablemente esperar que os acompañe siempre? ¿Por qué mostrarse tan deseoso de informaros de las grandes relaciones que habéis mantenido; las cosas obsequiosas que os dijeron; los honores, las distinciones que habéis recibido, como si éstas

${ }^{39}$ Hume, op. cit., Sección VIII, "De las cualidades inmediatamente amables a los demás", Parte I, párrafo 9, p. 137.

${ }^{40}$ Aquí encuentro una analogía con el carácter de signo que poseían las riquezas para el capitalismo puritano del protestantismo, las cuales resultaban sólo una señal de estar en la gracia, en el camino correcto de la salvación, como muestra Max Weber en su Ética protestante. De manera análoga, el aplauso público es sólo un signo de la moralidad, mas no posee un valor sustantivo, es decir, el ser moral no depende del aplauso, sino sólo es un reconocimiento del propio ser moral, no posee la última palabra del juicio moral. Lo sustantivo es ser digno de aplauso, lo cual descansa en el objeto de una acción considerada valiosa tanto por el agente como por la comunidad. 
no fueran obvias, y que podríamos [...] habernos imaginado por nosotros mismos sin que se nos dijeran? ${ }^{41}$

Vemos en la postura de Hume cómo la construcción de la dignidad humana no depende de la valoración o reconocimiento de la opinión pública de manera determinante, sino de la apreciación que el sujeto tiene de sí mismo ante su conciencia; esto implica ya un principio de "autonomía" moral en el "tribunal de la conciencia", implícito en la moralidad humeana previa a la postulación kantiana, que podemos rastrear también en el sistema de moralidad smithiano con su "espectador imparcial".

\section{El origen de la justicia humeana frente a la paradoja mandevilliana}

En la Investigación sobre los principios de la moral, Hume establece que la virtud de la justicia es artificial o convencional; demuestra cómo su necesidad se deriva de un desorden, tanto de las imperfecciones de la propia naturaleza-la escasez de satisfactores-como de nuestras relaciones sociales, es decir, el mérito de la justicia descansa en su utilidad pública; es virtud en tanto su finalidad es promover la felicidad humana y la búsqueda del máximo de felicidad. Bajo esta perspectiva, podemos conectar la tesis humeana con la paradoja mandevilliana de "vicios privados hacen virtudes públicas", en tanto dichos desórdenes o vicios dentro de la terminología mandevilliana ${ }^{42}$ justifican el surgimiento de ciertas virtudes públicas como la justicia, la ley, el Estado, las profesiones y los productos culturales. El mal social o natural explican la necesidad de las profesiones y artes que los normen, regulen y neutralicen.

Al estudiar las analogías entre ambos filósofos en torno a las pasiones encontramos una opinión similar que afirma que el dolor del sujeto ante el sufrimiento del prójimo depende de la cercanía del objeto que causa la impresión. Hume acepta la diferencia de grados que nos causan las

${ }^{41}$ Hume, op. cit., Sección VIII, "De las cualidades inmediatamente amables a los demás", Parte I, párrafo 9, p. 137.

${ }^{42} \mathrm{Si}$ bien Mandeville se refiere al significado de vicio como "aquello que perjudica a los demás", me limitaré a la noción de vicio como desorden y a la necesidad de que algo lo regule. 
impresiones; sin embargo, niega la afirmación de Mandeville acerca de las acciones benevolentes, pues considera que la ayuda al prójimo obedece exclusivamente a la molestia que causa la impresión de su dolor, una muestra más de escepticismo en torno a la caridad como virtud. En cambio, Hume sí cree en la posibilidad de un "sentimiento humanitario" innato, aunque al igual que Mandeville, encuentra ciertos peligros de las acciones caritativas de cara a la utilidad pública, como el caso de un juez débil que exonere de castigo a un delincuente, en cuyo caso se viola el "principio de justicia" y se peca contra la sociedad; actos así promueven la disolución de la sociedad. Rechaza el mérito de la caridad para la utilidad pública porque podría fomentar la ociosidad y la depravación de la sociedad:

El dar limosna a los mendigos ordinarios es algo que se elogia de forma natural, porque parece aliviar la situación de los indigentes y afligidos. Pero cuando observamos el estímulo que ello proporciona a la ociosidad y a la depravación, consideramos a esta clase de caridad más como una debilidad que como una virtud. ${ }^{43}$

Hume hace una referencia directa a Mandeville cuando analiza la evolución histórica del lujo, asociado por lo general con el vicio de corrupción y transformado históricamente gracias a su utilidad social en las sociedades modernas. Este cambio de sentido y valoración del concepto del lujo fue posible gracias a aquellos filósofos menos rigoristas, quienes pudieron probar sus ventajas:

Durante mucho tiempo se consideró al lujo [...] como la fuente de toda corrupción de gobierno [...] se le juzgó universalmente como un vicio [...] tema de declamación para todos los autores satíricos y moralistas severos. Aquellos que prueban [...] que tales refinamientos tienden más bien al incremento de la laboriosidad, de la civilización, de las artes, regulan de nuevo tanto nuestros sentimientos morales como políticos, y representan como laudable o inocente lo que anteriormente se había considerado como pernicioso y censurable. ${ }^{44}$

\footnotetext{
${ }^{43}$ Hume, op. cit., Sección II, “De la benevolencia”, Parte II, párrafo 12, p. 44.

${ }^{44}$ Ibid., párrafo 15, p. 45.
} 
Aquello que pretendía mostrar Hume en su investigación era cómo el mérito y la aprobación de los sentimientos morales descansaban en su carácter de utilidad pública y no en el provecho personal y privado. Así, va a demostrar el mérito de la justicia y su carácter convencional y no innato, pues no existe la justicia natural. La justicia es posible por la escasez: si viviésemos en abundancia y los recursos no fuesen limitados no habría razón para su existencia, no sería una virtud, carecería de mérito por su inutilidad para promover una mayor felicidad a la humanidad. Para probarlo, reduce al absurdo dos casos hipotéticos, uno en el que retrata a una sociedad en abundancia y otra en donde impera la escasez; en esta última se hace necesaria la justicia, su utilidad para la sociedad es lo que la convierte en una virtud, de lo contrario no merecería ese nombre.

Hume legitima estados de excepción del derecho, por ejemplo, es legítimo para una comunidad que sufre hambre abrir los graneros de sus propietarios, pues las leyes de propiedad quedan suspendidas por su inutilidad, en tanto no favorecen en ese momento la felicidad de la sociedad. En la guerra lo mismo, las "reglas de la justicia" quedan abolidas para ambos bandos. En situación de amenaza extrema las leyes de la prudencia y de la autoconservación legitiman la inobservancia de la ley en función de su inutilidad:

Las reglas de la equidad o justicia dependen completamente del estado y condición particulares en que se encuentran colocados los hombres [...] Al convertir a la justicia en totalmente inútil, destruís totalmente su esencia y suspendéis su carácter obligatorio para la humanidad. ${ }^{45}$

Para Hume, ser justos no es parte de nuestra naturaleza, con lo cual Mandeville estaría de acuerdo: seguimos los dictados de nuestro corazón, somos parciales con respecto a nosotros mismos y nuestros amigos, pero ello no evita que aprendamos las ventajas de la equidad. El bien de la humanidad es el único objetivo de las leyes y regulaciones, es decir, la finalidad de la política es la felicidad pública. Estas ideas se contra-

${ }^{45}$ David Hume, Investigación sobre los principios de la moral, op. cit., "De la justicia", Parte I, párrafo 12, p. 52. 
dicen con la legitimación que hace de la desigualdad social, en la que encuentra el fundamento del progreso, la promoción del trabajo, del comercio y de las artes, de manera análoga a como lo hace Mandeville. Se opone a la igualdad de las posesiones: la desigualdad entre los hombres surge en cuanto las habilidades se desarrollan. La igualdad aboliría las jerarquías, empobrecería a la sociedad como un todo y haría innecesaria la existencia de un gobierno:

Por muy plausibles que puedan parecer estas ideas de la igualdad perfecta $[\ldots]$ son impracticables [...] aunque no lo fueran, resultarían extremadamente perniciosas para la sociedad humana [...] sus diferentes grados de habilidad, cuidado y aplicación destruirín inmediatamente esa igualdad [...] si controláis esas virtudes, reduciréis la sociedad a la indigencia extrema, y en vez de evitar la pobreza y la miseria de unos pocos, las haréis inevitables para toda la comunidad [...] La perfecta igualdad de posesiones, al destruir toda jerarquía debilita [...] la autoridad de los magistrados $[\ldots]$ Tiene que reducir todo el poder casi a un mismo nivel. ${ }^{46}$

Esta cita es una clara legitimación de la desigualdad como fundamento de la riqueza, del progreso y de la existencia del gobierno, lo cual contradice su defensa en favor del "sentimiento humanitario", como precondición y sentido moral innato necesario para la armonización social, así como de los ideales democráticos en favor de un cambio de posiciones en el debate público, del principio de la tolerancia y de la simpatía como condición de posibilidad de la comunicación intersubjetiva. Paradójicamente, las diferencias de la propiedad y la desigualdad entre clases posibilitan el poder de un gobierno en el planteamiento humeano. Una sociedad igualitaria es imposible a nivel fáctico, y en caso de serlo, sería perniciosa para la humanidad; pero lo es sólo porque en su concepto de "humanidad" está considerando a un conjunto de propietarios privados; lo mismo ocurrirá a Mandeville, cuando hable de beneficios públicos o aquello que considera "sociedad civil".

Para Hume, al igual que para Mandeville, el comercio es posible y deriva su utilidad de las diferencias en las habilidades entre los hombres,

${ }^{46}$ Ibid., Parte II, párrafo 5, p. 60. 
de la división del trabajo y de sus diferencias de propiedad. Hipostasía el interés de un grupo de propietarios y comerciantes con el interés de la humanidad:

Y ese comercio que es tan beneficioso para la sociedad humana; $y$ que todos los contratos y promesas deberían cumplirse escrupulosamente a fin de mantener esa seguridad y confianza mutuas que tanto promueven el interés general de la humanidad. ${ }^{47}$

El comercio no sería posible sin las diferencias entre los miembros de la sociedad, es necesaria la especialización que da lugar a una adecuada división del trabajo. La desigualdad entre los hombres, aunada a la limitación de los recursos o escasez, es la fuente de estos intercambios. Hume defiende una preservación paradójica, en tanto la desigualdad social es útil a la conservación de la sociedad y evita su disolución:

Recurrimos a cada instante al principio de la utilidad pública [...] ¿En qué se convertiría el mundo si prevalecieran tales prácticas? ¿Cómo podría subsistir la sociedad bajo tales desórdenes? Si la distinción o la separación de posesiones fueran completamente inútiles, ¿puede alguien concebir que hubiera llegado alguna vez a prevalecer la sociedad? ${ }^{48}$

Hume llega a conclusiones análogas a la de "vicios privados, virtudes públicas" de Mandeville, en el sentido de cómo una tensión, una desigualdad, un mal social o natural (como la escasez) justifican la necesidad del derecho positivo, la existencia del Estado y del gobierno. Parte del hecho de que el hombre no es equitativo por naturaleza dada la escasez de medios para su propia preservación; si el hombre fuese tan sagaz para saber de manera natural la conveniencia de tomar en cuenta el interés de los demás y viviese en armonía permanente con otros hombres a lo largo de su existencia, ¿qué necesidad habría de la justicia y del gobierno? Pues la virtud de la justicia recibe su mérito del

${ }^{47}$ Ibid., párrafo 7, p. 61.

${ }^{48} \mathrm{Ibid}$, párrafo 26, p. 70. 
CRISTINA RÍOS ESPINOSA

desorden en las relaciones sociales y posibilita la existencia de una sociedad política:

Si todo hombre tuviese la sagacidad suficiente para percibir [...] el fuerte interés que lo ata a la observancia de la justicia y la equidad, y el vigor mental suficiente para perseverar en una adherencia firme a un interés general y distante $[\ldots]$ nunca habría existido una cosa tal como el gobierno o la sociedad política. ${ }^{49}$

Esta opinión es análoga a la defendida por Mandeville acerca de la ausencia de una sociabilidad natural en el hombre. El desorden natural de la humanidad hace necesarios ciertos límites virtuosos que impongan el orden social, por ejemplo, la existencia de las profesiones. Los abogados no tendrían razón de existir si no existieran ladrones, lo mismo que los sacerdotes sin la existencia de pecadores, o los médicos sin enfermos; de igual forma, el Estado y sus leyes son necesarios ante la insociabilidad de los egoístas mandevillianos. La tarea legislativa no será moralizar, sino fomentar instituciones que promuevan el orden social, las cuales son convencionales al igual que nuestro carácter social. Al igual que Mandeville, Hume destaca la relatividad de las leyes civiles y las costumbres debido a su referencia a la utilidad pública, es decir, el sentido de la existen116 cia de las leyes obedece a su carácter de estar referido a su utilidad social. Todo mérito moral está en función de esta utilidad, como ya observamos antes. Muestra la necesidad de algunas reglas de conducta aun en las sociedades inmorales; la función o razón de ser de dichas reglas es la preservación de dicha sociedad de su disolución.

Hume llega a una conclusión a la que ya Hobbes, primero, y luego Mandeville, habían llegado previamente, aquella que reconocía cómo la disposición convencional del hombre a la sociabilidad respondía a una toma de conciencia, a saber, al reconocimiento interior acerca de la necesidad de promover el interés público como útil a la realización de la propia preservación:

A menudo se ha afirmado que como todo hombre tiene una fuerte conexión con la sociedad y percibe la imposibilidad de su subsistencia

${ }^{49}$ Ibid., Sección IV, “De la sociedad política”, Parte I, párrafo 1, p. 72. 
solitaria, se convierte con base en esto en partidario de todos esos hábitos o principios que promueven el orden de la sociedad [...] Tanto como valoremos nuestra propia felicidad y bienestar, así debemos aplaudir la práctica de la justicia y de la humanidad, pues sólo gracias a ellas puede mantenerse la unión social y recoger cada hombre los frutos de la asistencia y protección mutuas. ${ }^{50}$

La obligatoriedad política de la "sociedad de mercado" responde a este factor común, al mutuo reconocimiento acerca de la imposibilidad de alcanzar la felicidad privada sin promover al mismo tiempo la felicidad pública.

\section{Conclusiones}

En la comparación entre estos dos sistemas de moralidad encuentro tres diferencias teóricas importantes y una semejanza. En primer lugar, la creencia de Hume en un "sentimiento humanitario" innato que hace que el hombre se preocupe activamente por la felicidad de los demás como un fin en sí mismo; dicho sentimiento es una precondición necesaria para la sociabilidad por medio de la educación y la manipulación política. La certeza del acto moral descansa en la felicidad pública como fin en sí mismo. En cambio, Mandeville negará la existencia de dicho "sentimiento humanitario" como algo innato, pues el origen de la sociabilidad descansa en el egoísmo, en la conveniencia o utilidad de una acción en favor de la felicidad pública, que posibilita la realización de la propia felicidad. La paradoja mandevilliana descansa en que las mismas acciones egoístas son las que permiten la sociabilidad y la gobernabilidad del Estado, sin importar la moralidad del agente ni si la armonía social fue el resultado de un "sentimiento humanitario" original o producto de la conveniencia, de la simulación, la hipocresía o del utilitarismo privado.

La segunda diferencia entre ambos autores es su postura en torno a un "sentido moral": mientras que para Hume las virtudes sociales

\footnotetext{
${ }^{50}$ Hume, op. cit., Sección V, “¿Por qué agrada la utilidad?”, Parte I, párrafo 5, p. 82.
} 
requieren de una precondición lógica llamada "sentido moral" (moral sense), pues de lo contrario se hace imposible la educación moral de los agentes, para Mandeville no existe tal "sentido moral" originario, sino que será el resultado de una construcción política y educativa, de una arquitectónica sociopolítica heterónoma combinada con un avance civilizatorio espontáneo a lo largo de la historia.

La tercera diferencia importante entre ambos filósofos radica en su tratamiento en torno a la dignidad y honorabilidad de los sujetos. Para Hume, la dignidad del sujeto no depende de la "heteronomía", es decir, no depende primariamente de la opinión pública y de su aplauso, como sí lo hace en el planteamiento de Mandeville, quien queda encerrado en el reconocimiento social, con lo cual el sujeto no es verdaderamente autónomo y es plenamente manipulable por la opinión.

Uno de los puntos de encuentro entre ambos filósofos es la defensa de la desigualdad como fuente del comercio, las profesiones, la justicia y el gobierno. En el análisis que hace Hume del origen y necesidad de la justicia, tanto en su obra El Tratado de la naturaleza humana como en La Investigación sobre los principios de la moral, encuentro similitudes con el origen de la sociedad de Mandeville en La Fábula de las abejas. En la necesidad de la justicia y de su utilidad analizada por Hume se pueden encontrar conclusiones análogas a las de "vicios privados, virtudes públicas" de Mandeville, en el sentido de cómo una tensión, una desigualdad, un mal social o natural (como la escasez) justifican la necesidad del derecho positivo, la existencia del Estado y del gobierno. Defensas ideológicas como éstas son insostenibles para la reproducción social de los ciudadanos de un Estado que se dice liberal; tesis semejantes tienen una vigencia inusitada hoy en día ante la reproducción ampliada de la pobreza, los trabajos precarios y el totalitarismo del mercado con sus monopolios y oligarquías; hoy más que nunca se vuelve necesaria la crítica filosófica y el desenmascaramiento de las contradicciones de estas teorías para la defensa de la vida de los pueblos. 